\title{
CALCIUM DEPENDENT RESPONSES OF VASCULAR SMOOTH MUSCLES IN PREGNANT AND NON PREGNANT RATS
}

\section{'A. A. Aigbiremolen, ${ }^{2} \mathrm{C}$ P Aloamaka and ${ }^{2} \mathrm{O}$. M. Odigie}

\begin{abstract}
'Department of Human Physiology, Faculty of Basic Medical Sciences, College of Medicine, Ambrose Alli University, Ekpoma, Edo State, Nigeria
\end{abstract}

2Department of Human Physiology, Faculty of Basic Medical Sciences, College of Health Sciences, Delta State University, Abraka, Delta State, Nigeria

Email: osgiedeprof@yahoo.com

\begin{abstract}
In pregnancy, control mechanism(s) for change in regional blood flow remains inexplicable. However, the overriding are reportedly due to vasodilation, implicating primary haemodynamic alteration in vasodilatation to increase circulating blood volume and cardiac output. In this study, we investigated and compared in pregnant and non-pregnant wistar rats (using the student t-test), the effect of administration of variable doses of calcium $\left(\mathrm{Ca}^{2+}\right)$ on smooth muscle contraction. Thirty five (35) Wistar rats of between $200 \mathrm{~g}-250 \mathrm{~g}$ were procured, acclimatized (for two weeks) and randomly selected into seven (7) groups of five (5) rats each. Each group were fed (for 21 days), with variable doses of $200 \mathrm{mg} / \mathrm{kg}$ body weight (bw.), $250 \mathrm{mg} / \mathrm{kg} \mathrm{bw,} 500 \mathrm{mg} / \mathrm{kg} \mathrm{bw}, 750 \mathrm{mg} / \mathrm{kg} \mathrm{bw}, 1000 \mathrm{mg} / \mathrm{kg} \mathrm{bw,} 1250$ $\mathrm{mg} / \mathrm{kg}$ bw and $1500 \mathrm{mg} / \mathrm{kg}$ bw of calcium $\left(\mathrm{Ca}^{2+}\right)$ respectively. After twenty-one (21) days of administration of test substance, the rats were sacrificed via cervical dislocation, vascular smooth muscle (from aortic blood vessels) isolated and processed in organ bath to obtain maximum contraction strengths, tension and stretch. The rings from pregnant and nonpregnant rats were dipped in normal physiological salt solution (PSS) (0.9 Molar solution of $\mathrm{NaCl}$ ) to observe for concentration dependency. From our result, contractile responses to phenylephrine of rings from non-pregnant rats in both PSS and $0.8 \mathrm{mM}$ PSS were significantly increased $(p<0.05)$ than the corresponding responses of rings from pregnant rats. Also, exposure of rings from pregnant and non-pregnant rats to $0.8 \mathrm{mM} \mathrm{Ca}^{2+}$ PSS solution caused a statistically significant $(p<0.05)$ decrease in the contractions of the respective rings to phenylephrine. Mean $\mathrm{EC}_{50}$ values were also seen to increase significantly $(\mathrm{p}<0.05)$ by exposure of the rings to $0.8 \mathrm{mM} \mathrm{Ca}^{2+}$ PSS, with the increase being greater with respect to rings from non-pregnant rats. Further studies to corroborate the result of this findings are highly recommended.
\end{abstract}

Keywords: Calcium, Pregnancy, smooth muscle 


\section{INTRODUCTION}

Normal pregnancy is associated with a progressive increase in plasma and intracellular fluid volume, and with a rise in cardiac output [1]. This rise is likely to be adaptation via renal sodium retention induced by the hormonal influence [2]. The causes of vasodilation include an arteriovenous shunt in the maternal circulation due to the pressure of placenta prostaglandins produced by the endothelial cells and high level of progesterone and oestrogen. The result of these vasodilatory forces imposed on the pressor response to evogenous angiotensin II is a reduced pressor response [3]. Plasma levels of atrial natriuretic factor are normal [4]. In association with the increased blood volume, peripheral oedema is common, which arises from interference of venous return by enlarged uterus [5]. There have been numerous reports on changes in normotensive pregnancy, including a decrease in erythrocyte sodium concentration and increase in Oubainsensitive sodium flux, the sodium pump rate constant and maximum velocity [6].

The mechanism(s) controlling the regional changes in blood flow in pregnancy are unknown. However, the overriding influence is vasodilator [1], suggestive that the primary haemodynamic alteration in pregnancy is vasodilatation followed by increases in circulating blood volume and cardiac output.

In a number of studies angiotensin II, has also been attributed to an altered arterial responsiveness [7]. The studies by Assali's group on ganglion blocking agents is of considerable interest [8]. The report actually determined the mechanisms regulating the haemodynamic changes in the pregnant women and the relationship to the hypertension of toxemia of pregnancy. An intravenous injection of $400 \mathrm{mg}$ of tetraethyl ammonium chloride (TEAC), a drug which blocks the autonomic system at the ganglia, was given to normal non-pregnant and pregnant women. In the non-pregnant subjects, there was little effect on blood pressure: the systolic pressure fell on the average by $8 \%$ the diastolic by $4 \%$. In pregnant women, the effect was striking and increased throughout the pregnancy until, in the third trimester: the mean fall of systolic blood pressure was $40 \%$ and of diastolic $37 \%$. Two or three days after delivery, the effect had disappeared.

Assail et al, were interested primarily in the fact that this did not occur in women with pre-eclampsia, or indeed in women who did not develop clinical preeclampsia. It was therefore suggested that vessel tone in pre-eclampsia is maintained by humoral agent, Crestani et al (2017), therefore suggested that the humoral agent may be angiotensin II eclampsia is maintained by humoral agent. Crestani et al, therefore suggested that the humoral agent may be angiotensin II [9].

During pregnancy, women are relatively resistant to pressor effects of exogenous angiotensin $\|$ [2]. This is a reflection of the down regulation of angiotensin II receptors by high levels of 
circulating angiotensin II and antagonism by endothelium-derived vasodilating prostacyclin and nitric oxide [2]. Also, the placenta is less responsive to angiotension II than most non reproductive tissues. This result in preferential maintenance of perfusion through the utero-placental bed [10]. The vessel tone in normal pregnancy is so much more dependent on sympathetic control than before pregnancy: this suggests that the autonomic nervous system is correcting for the effect of active vasodilator substance.

During pregnancy the maternal vasculature dilates and becomes subsensitive to the vasoconstrictor effects of angiotensin II and sympathetic constrictor stimuli [14]. It is suspected that blood borne substances including increased oestrogen and augmented output of the endothelial cell-derived vasodilator autacoids prostacyclin (PGI2) and nitric oxide (NO) could be involved [13] in non-pregnant animals oestrogen administration mimics pregnancy by causing decreased vascular sensitivity to angiotensin II [15].

\section{Aim of Study}

This study aimed at investigating the changes in vascular smooth muscles of pregnant and non-pregnant rats occasioned by administration of variable concentrations of calcium ion solutions. Specifically, the study;

i. Examined the effects $\mathrm{Ca}^{2+}$ solution on vascular smooth muscle tone

ii. Determined the effects different doses of $\mathrm{Ca}^{2+}$ solution on vascular smooth muscle contraction iii. Comparatively evaluate the dose dependent changes in vascular smooth for different doses of $\mathrm{Ca}^{2+}$ treatment to pregnant and nonpregnant rats

\section{Materials and Method}

\section{Study Design:}

Thirty five (35) wistar rats of between $200 \mathrm{~g}-250 \mathrm{~g}$ were procured, acclimatized (for two weeks) and randomly selected into seven (7) groups of five (5) rats each. Each group were fed (for 21 days), with variable doses of $200 \mathrm{mg} / \mathrm{kg}$ body weight (bw.), $250 \mathrm{mg} / \mathrm{kg}$ bw, $500 \mathrm{mg} / \mathrm{kg}$ bw, 750 $\mathrm{mg} / \mathrm{kg} \mathrm{bw}, 1000 \mathrm{mg} / \mathrm{kg}$ bw, $1250 \mathrm{mg} / \mathrm{kg}$ bw and $1500 \mathrm{mg} / \mathrm{kg}$ bw of calcium $\left(\mathrm{Ca}^{2+}\right)$ respectively. After twenty-one (21) days of administration of test substance, the rats were sacrificed via cervical dislocation, vascular smooth muscle (from aortic blood vessels) isolated and processed in organ bath to obtain maximum contraction strengths, tension and stretch. In any case, obtained data were compared for pregnant and non-pregnant rats

\section{Tissue Preparation}

The rats were sacrificed by stunning and decapitation. The tissues were prepared using standard methods for the study of isolated blood vessels as used by several workers [11]. The descending aorta were quickly removed, put in a petri dish containing physiological salt solution (PSS) and cleared of all adhering connective tissues. The aorta was then cut into $2 \mathrm{~mm}$ ring segments and each segment was suspended between two L-shaped holders. 
The lower holder was fixed to the base of $20 \mathrm{ml}$ organ baths containing physiological salt solution (PSS) while the upper holder was connected to check transducer coupled to Ugo Bassil recorder. The aortic rings were studied under standard organ bath condition of temperature at $370^{\circ} \mathrm{C}$, and $\mathrm{pH} 7.4$ and the PSS was bubbled with $95 \% \mathrm{O}_{2}, 5 \% \mathrm{CO}_{2}$ gas mixture. In some experiments the endothelium of the blood vessels were removed mechanically by gently rubbing the intimal aspects of the blood vessel rings with a roughened needle. The presence of functional endothelium was ascertained by the observation of at least $42 \%$ relaxation to 10 ${ }^{7} \mathrm{M}$ acetylcholine. A passive resting tension of $1 \mathrm{gm}$ was applied to each ring, this was the tension at which maximum responses to $10^{-5} \mathrm{M}$ phenylephrine was obtained (Figure 2). An equilibrium period of 90 minutes was allowed before the commencement of the measurements. During the equilibration period, the aortic rings were rinsed at about $30 \mathrm{~min}$ interval. During this time the rings were stimulated with $10^{-7} \mathrm{M}$ phenylephrine contraction response of rat aorta to 10-5 $\mathrm{M}$ Phenylephrine, following different levels of stretch

\section{Concentration \\ Response \\ Phenylephrine \\ Test to}

The aortic rings from pregnant and non-pregnant rats were suspended in either normal physiological salt solution (PSS) or $0.8 \mathrm{mM} \mathrm{CaCl}_{2}$ PSS, and exposed to increased concentration of phenylephrine (10-9-10-4M). This was done by cumulatively increasing the concentrations of phenylephrine in the bath. A subsequent application of phenylephrine was done when the effect of the earlier application had become stable. The contractile responses to phenylephrine of rings from pregnant and non-pregnant rats in the respective physiological salt solutions were compared. The protocol was also applied on rings of blood vessel from pregnant and non-pregnant rats from which the endothelium had been removed.

\section{Analytical Approach}

Results were presented as Means \pm SEM. Statistical analyses were carried out using the statistical package for social sciences (SPSS) version 21. Student t-test was used to compare the differences between the groups. $\mathrm{p}$-value $<0.05$ was considered significant.

\section{Results}


Table 1: Maximal Contractions of Aortic Rings to Phenylephrine for Pregnant and Non-Pregnant Rats in Normal and 0.8mM Calcium Chloride Physiological Salt Solution (CaCl PSS)

\begin{tabular}{lcc}
\hline \multicolumn{1}{c}{ Rats } & EC $_{\mathbf{5 0}}$ & Max. Contraction \\
\hline Pregnant (In Normal PSS n=10) & $2.47( \pm 0.31) \times 10^{-7} *$ & $1139 \pm 103.4^{*}$ \\
\hline Non-pregnant (In Normal PSS n=10) & $6.57( \pm 0.80) \times 10^{-8}$ & $19095 \pm 82.3$ \\
\hline Pregnant (0.8mM PSS) & $4.1( \pm 0.5) \times 10^{-7}$ & $880 \pm 25.95$ \\
\hline Non-pregnant (0.8mM PSS) & $1.9( \pm 0.8) \times 10^{-7+}$ & $1300.85 \pm 57.36$ \\
\hline
\end{tabular}

Table II: Maximal Contraction Response of Aortic Rings to Phenylephrine of Pregnant and NonPregnant Rats to Normal and 0.8mM Calcium Chloride Physiological Salt Solution (CaCl PSS)

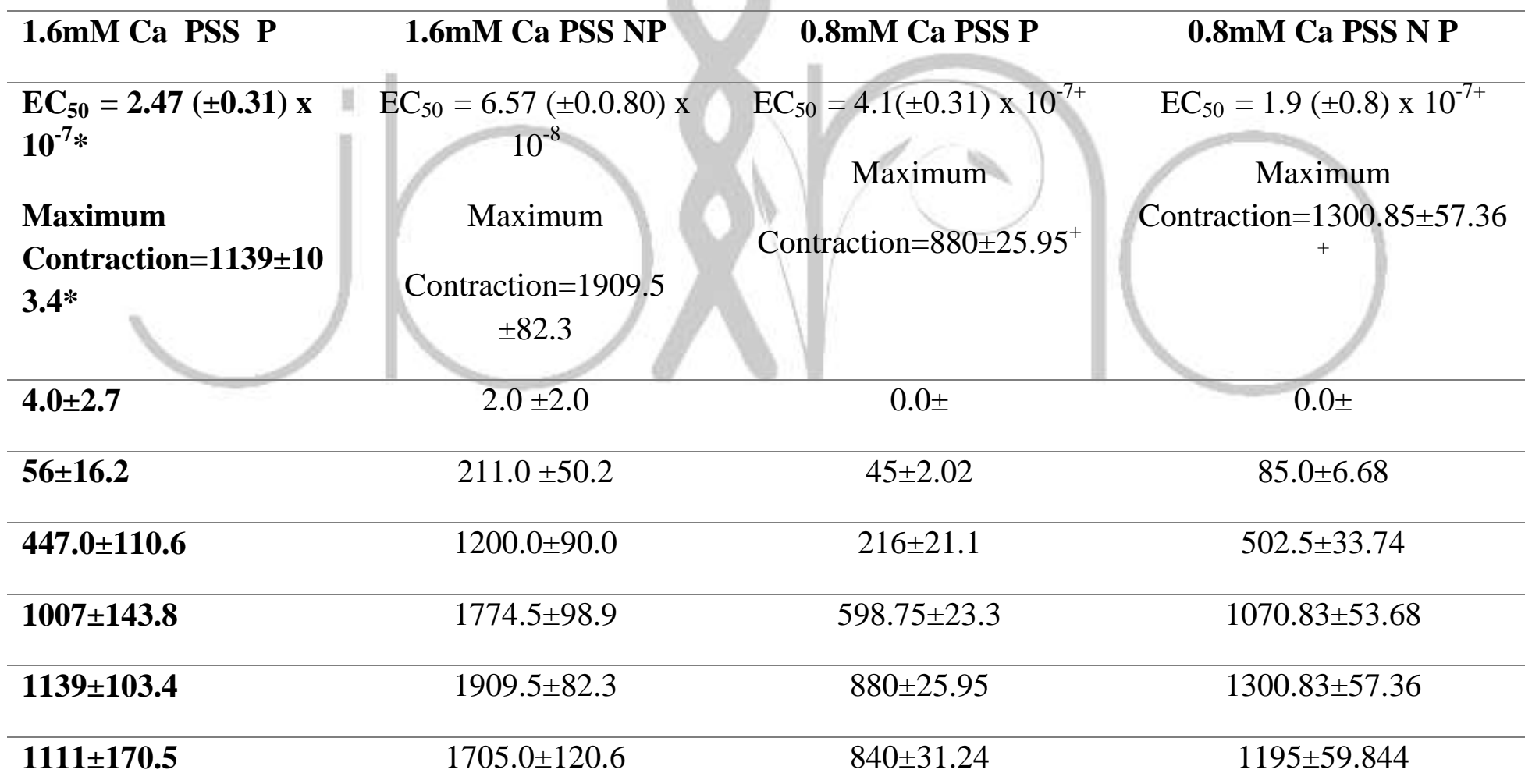

From table II (above), exposure of rings from pregnant and the non-pregnant rats to $0.8 \mathrm{mM} \mathrm{CaCl}$ PSS significantly decreased $(\mathrm{p}<0.05)$ the contractions of the respective rings to phenylephrine. The maximal contractions, in rings from pregnant and non-pregnant rats decreased by $22.7 \%(259 \mathrm{mg})$ and $31.9 \%(609 \mathrm{mg})$ respectively by exposure of the rings to $0.8 \mathrm{mM} \mathrm{Ca}^{2+} \mathrm{PSS}$. The $\mathrm{EC}_{50}$ values were also significantly $(\mathrm{p}<0.05)$ increased by exposure of the rings to $0.8 \mathrm{mM} \mathrm{Ca}^{2+}$ - PSS, with the increase being greater with respect to rings from non-pregnant rats. 
Fig. I Concentration response curves for phenylephrine of aortic rings from pregnant and non-pregnant rats.

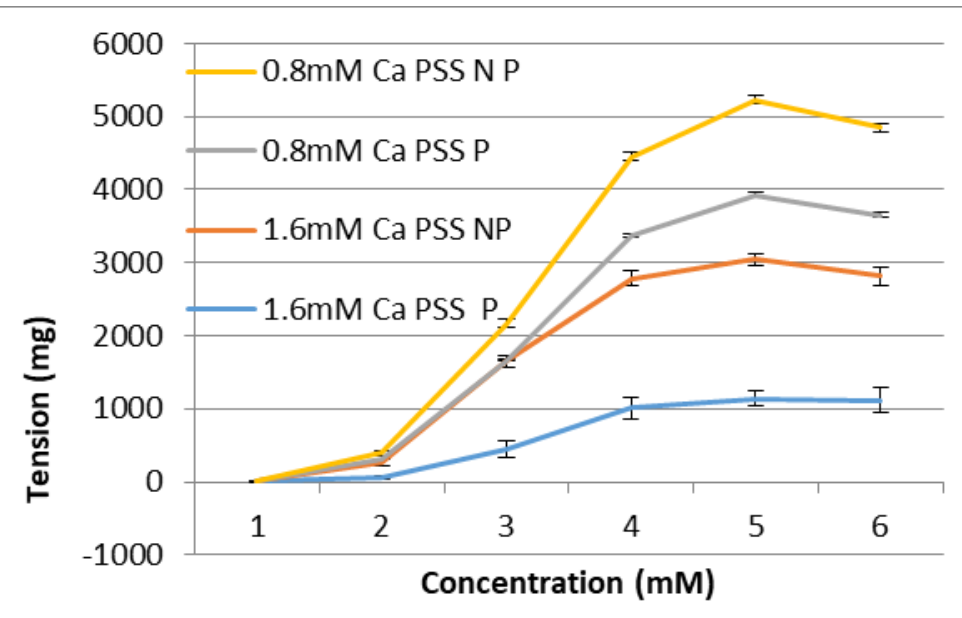

From above figure, removal of endothelium from the rings from the pregnant and the non-pregnant rats in normal PSS significantly increased the contractions of the rings to phenylephrine (Fig. 4). The contractions to phenylephrine of the de-endothelialized rings from pregnant rats were not significantly different from those of non-pregnant rats. The EC50 values for responses and the maximal contractions of the de-endothelialized rings were not significantly different.

Table III: Maximal Contractions Values (mg) to Phenylephrine of Aortic Rings from De- Endothelialized Pregnant and Non-Pregnant Rats

\begin{tabular}{lll}
\multicolumn{1}{c}{ Rats } & \multicolumn{1}{c}{ EC $_{\mathbf{5 0}}$} & \multicolumn{1}{c}{ Max. Contraction } \\
\hline Pregnant $(\mathbf{n}=\mathbf{1 0})-\mathbf{E}$ & $4.9( \pm 0.9) \times 10^{-8 *}$ & $2181 \pm 145.4^{*}$ \\
\hline Pregnant $(\mathbf{n = 1 0})+\mathbf{E}$ & $2.47( \pm 0.31) \times 10^{-7}$ & $1139.0 \pm 103.4$ \\
\hline Non-Pregnant $(\mathbf{n = 1 0})-\mathbf{E}$ & $2.35( \pm 0.51) \times 10^{-8}$ & $2012 \pm 63.4$ \\
\hline Non-pregnant $(\mathbf{n = 1 0})+\mathbf{E}$ & $6.57( \pm 0.80) \times 10^{-8}$ & $1909.5 \pm 82.3$ \\
\hline
\end{tabular}

Fig. II: Concentration response test of phenylephrine of rings from de-endothelialized ring from pregnant and non-pregnant rats. ${ }^{*} \mathrm{p}<0.05$; compared with the corresponding $+\mathrm{E}$ pregnant value 
Table IV: Maximal Contraction Response to Phenylephrine of Aortic Rings from De-Endothelialised Pregnant and Non-Pregnant Rats

\begin{tabular}{|c|c|c|c|}
\hline 1.6mM Ca PSS NP (-E) & 1.6mM Ca PSS P(+E) & 1.6mM Ca PSS P & 1.6mM Ca PSS NP \\
\hline $\begin{array}{l}\mathrm{EC}_{50}=4.9( \pm 0.9) \times 10^{-8} * \\
\text { Maximum }\end{array}$ & $\underset{7_{*}}{\mathrm{EC}_{50}}=2.47( \pm 0.31) \times 10^{-}$ & $\begin{array}{l}\mathrm{EC}_{50}=2.35( \pm 0.51) \times 10^{-8} \\
\text { Maximum }\end{array}$ & $\begin{array}{l}\mathrm{EC}_{50}=6.57( \pm 0.0 .80) \mathrm{x} \\
10^{-8}\end{array}$ \\
\hline $\begin{array}{l}\text { Contraction }=2181 \pm 145 \text {. } \\
4 *\end{array}$ & $\begin{array}{l}\text { Maximum } \\
\text { Contraction=1139 } \pm 103.4 \\
*\end{array}$ & Contraction $=2012 \pm 63.4$ & $\begin{array}{l}\text { Maximum } \\
\text { Contraction=1909.5 } \\
\pm 82.3\end{array}$ \\
\hline $45 \pm 17.7$ & $4.0 \pm 2.7$ & $105 \pm 47.8$ & $2.0 \pm 2.0$ \\
\hline $412 \pm 106.5$ & $56 \pm 16.2$ & $839 \pm 171.8$ & $211.0 \pm 50.2$ \\
\hline $1530 \pm 137.8$ & $447.0 \pm 110.6$ & $1663 \pm 98$ & $1200.0 \pm 90.0$ \\
\hline $2040 \pm 144.7$ & $1007 \pm 143.8$ & $1954 \pm 61.9$ & $1774.5 \pm 98.9$ \\
\hline $2181 \pm 145.4$ & $1139 \pm 103.4$ & $2012 \pm 63.4$ & $1909.5 \pm 82.3$ \\
\hline $2112 \pm 126.0$ & $1111 \pm 170.5$ & $1870 \pm 117.6$ & $1705.0 \pm 120.6$ \\
\hline
\end{tabular}

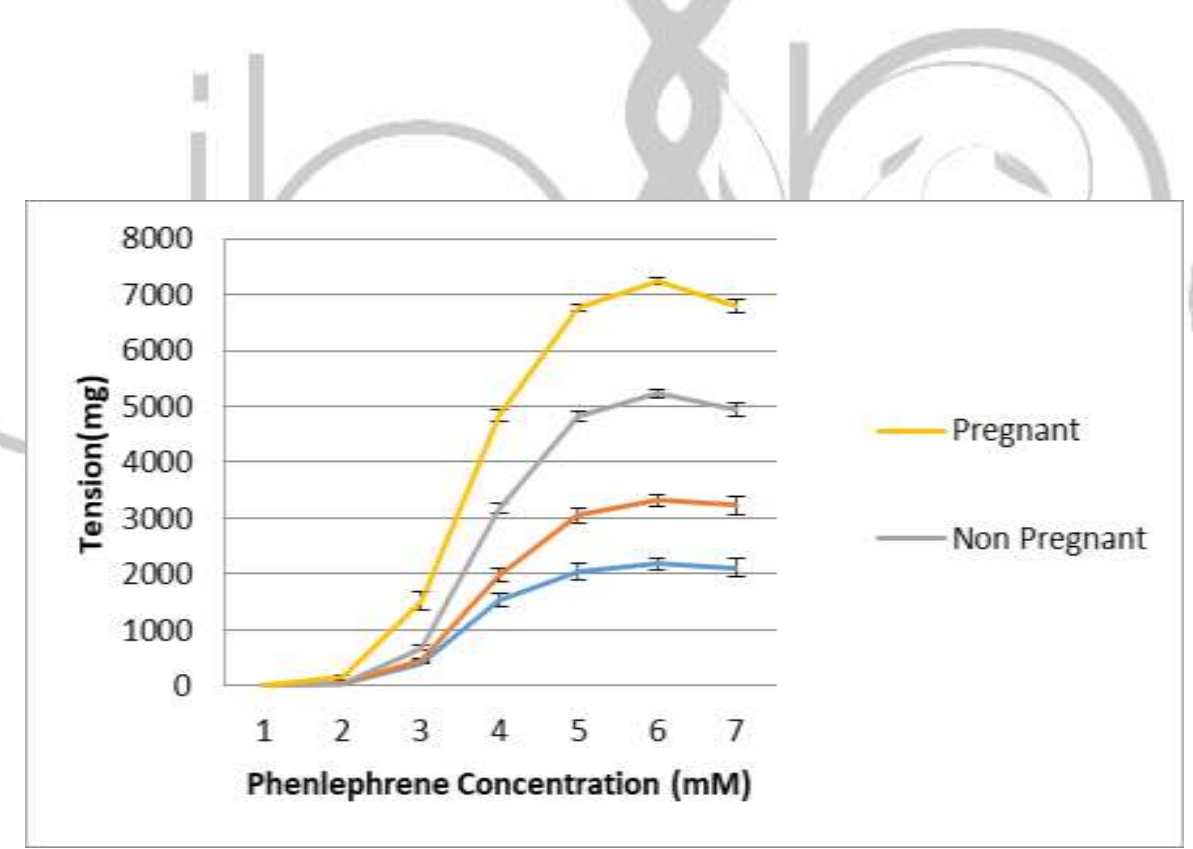

Fig. II: Concentration response test of phenylephrine of rings from de-endothelialized ring from pregnant and non-pregnant rats.

\section{Discussion}

Transport systems present in cell membrane control the movement of sodium, potassium, calcium and other ions in order to maintain the marked difference in concentration of these ions on the outside and inside of cells, which in turn, provide the electrochemical gradient needed for various cell functions. Abnormalities of the physical properties of the membrane and multiple transport system are the implicated pathogenesis of ino.com I Innovative Association 
hypertension. Majority of what follows are related to vascular smooth muscle cells [11], especially in hypertensive rats and human [12]. In this study, we investigated

the changes in vascular smooth muscles of pregnant and non-pregnant rats due to administration of variable concentrations of calcium ion solutions. From our observation, contractile responses of aortic ring to phenylephrine in non-pregnant rats for both physiological salt solution (PSS) and $0.8 \mathrm{mM}$ PSS were significantly increased ( $p<0.05)$ than the corresponding responses of rings in pregnant rats. Also, exposure of aortic rings from pregnant and non-pregnant rats to $0.8 \mathrm{mM} \mathrm{Ca}^{2+}$ PSS solution caused a statistically significant $(p<0.05)$ decrease in the contractions of the respective rings to phenylephrine. Mean $\mathrm{EC}_{50}$ values were also seen to increase significantly $(p<0.05)$ by exposure of the rings to $0.8 \mathrm{mM} \mathrm{Ca}^{2+} \mathrm{PSS}$, with the increase being greater with respect to rings from non-pregnant rats.

In normal pregnancy there are supporting evidence(s) of increased production of potent vasodilators, prostacyclin $\left(\mathrm{PGI}_{2}\right)$ and nitric oxide [11]. In support of the contention that the vascular endothelium is involved in the effect of pregnancy on vascular responses to vasoactive agent [11] was the observation that the attenuation of contractile responses to phenylephrine in pregnancy was abolished by endothelium removal [12].

The possibility that pregnancy produces its effect on vascular responses through inhibition of $\mathrm{Ca}^{2+}$ influx into vascular smooth muscle cells has not been conclusively investigated. It was however suggested that pregnancy may attenuate the contraction of blood vessel by decreasing calcium influx through the voltage operated calcium channels (VOCs) and the receptor operated calcium channel (ROCs) of vascular smooth muscle cells [10]. The observation in the present study will lend credence to the above notion: that is, that a decrease in the concentration of $\mathrm{CaCl}_{2}$ in the PSS from $1.6 \mathrm{mM}$ to $0.8 \mathrm{mM}$ caused greater decrease in the contractions of rings from non-pregnant rats compared with rings from pregnant rats. This will suggest a greater dependence of the smooth muscle cells of the blood vessel from nonpregnant rats on extracellular $\mathrm{Ca}^{2+}$ ions.

\section{Conclusion}

Vascular smooth muscle cells are highly differentiated and helpful in maintaining a contractile phenotype. Their contraction/relaxation is regulated by complex processes that are both calciumdependent, involving calcium channels and signalling pathways. In pregnancy, these processes are alternated, to increase production of potent vasodilators, prostacyclin $\left(\mathrm{PGI}_{2}\right)$ and nitric oxide. Thereby improves signalling pathways that are typically associated with contraction of vascular smooth muscles. Notwithstanding, complex interactions between traditional pro-contractile calcium-regulated signalling pathways and non-traditional contractile mechanisms often better the understanding of the intricacies of processes that underlie calcium induced, vascular smooth muscle activities in pregnant and non-pregnant states. It 
follows therefore that the possibility that pregnancy produces its effect on vascular responses through inhibition of $\mathrm{Ca}^{2+}$ influx into vascular smooth muscle cells through attenuation in contrast to the greater dependence of the smooth muscle cells of the blood vessel from non-pregnant rats on extracellular $\mathrm{Ca}^{2+}$ ions in vascular smooth muscle reactivity and contractility. This in effect lends credence to the calcium dependence activity status in vascular smooth muscles of pregnant and non pregnant states.

\section{References}

1. Godfraind T. Discovery and development of calcium channel blockers. Front Pharmacol 2017; 8:286.

2. Tabet F, Savoia C, Schiffrin EL, Touyz RM. Differential calcium regulation by hydrogen peroxide and superoxide in vascular smooth muscle cells from spontaneously hypertensive rats. J Cardiovasc Pharmacol 2004; 44:200-208.

3. Kosch $M$, Hausberg $M$, Barenbrock M, Posadzy-Malaczynska A, Rahn KH, Kisters K. Increased membraneous calcium concentrations in primary hypertension: a causal link to pathogenesis? I Hum Hypertens $2001 ; 15: 37-40.55$

4. Zamponi GW, Striessnig J, Koschak A, Dolphin AC. The physiology, pathology, and pharmacology of voltage-gated calcium channels and their future therapeutic potential. Pharmacol Rev 2015; 67:821-870. 57.

5. Zhou $Y$, Fan J, Zhu $H$, Ji L, Fan $W$, Kapoor I, Wang $Y$, Wang $Y$, Zhu $G$, Wang J. Aberrant splicing induced by dysregulated Rbfox2 produces enhanced function of $\mathrm{CaV} 12$ calcium channel and vascular myogenic tone in hypertension. Hypertension 2017; 70:1 183-1 193.

6. Giachini FR, Lima VV, Filgueira FP, Dorrance AM, Carvalho MH, Fortes ZB, Webb RC, Tostes RC. STIM1/Orail contributes to sex differences in vascular responses to calcium in spontaneously hypertensive rats. Clin Sci 2012; 122:215-222

7. . Behuliak $M$, Bencze $M$, Vaneckova' I, Kunes J, Zicha J. Basal and activated calcium sensitization mediated by RhoA/Rho kinase pathway in rats with genetic and salt hypertension. Biomed Res Int 2017; 2017:8029728.

8. Uehata $M$, Ishizaki $T$, Satoh $H$, Ono $T$, Kawahara T, Morishita T, Tamakawa $H$, Yamagami K, Inui J, Maekawa M, Narumiya S. Calcium sensitization of smooth muscle mediated by a Rhoassociated protein kinase in hypertension. Nature 1997; 389:990994.

9. Crestani S, Webb RC, da Silva-Santos JE. High-salt intake augments the 2020 September Edition | www.jbino.com | Innovative Association 
activity of the RhoA/ROCK pathway and reduces intracellular calcium in arteries from rats. Am J Hypertens 2017; 30:389-399

10.Sun Z, Li Z, Meininger GA. Mechanotransduction through fibronectin-integrin focal adhesion in microvascular smooth muscle cells: is calcium essential? Am J Physiol Heart Circ Physiol 2012; 302:H1965H1973.

11. Touyz RM. Reactive oxygen species as mediators of calcium signalling by angiotensin $\mathrm{Il}$ implications in vascular physiology and pathophysiology. Antioxid Redox Signal 2005; 7:1302-1308.

12. Zima AV, Blatter LA. Redox regulation of cardiac calcium channels and transporters. Cardiovasc Res 2006; 71:310-321.

13. Ezimokhai, M. and Ebeigbe, A. B. (1985) Reactivity of arterial smooth muscle from normotensive and preeclamptic women. West African Journal of Medicine, 4, 189-197.

14. Ezimokhai, M., Aloamaka, C. P., Cherian, T. (1993) Plasma from normal pregnant women alters the reactivity of rabbit aortic smooth muscle with functional endothelium. Clinical and Experimental Pharmacology and Physiology, 20,435-442.

15. De Swiet, M. (1991). The Cardiovascular System. In: Clinical Physiology in Obstetrics, 2nd edn (Ed. F. Hytten \& G. Chamberlain), Ch. 1. pp. 3-38. Blackwell Scientific Publications, Oxford.

16. Walters, W. A. W. \& Boura, A. L. A. (1993) Nitric oxide: The vascular endothelium and reproduction. Contemporary Reviews in Obstetrics and Gynaecology, 5, 207-213. 